\title{
NARRATIVAS DE INVESTIGAÇÃO E FORMAÇÃO EM EDUCAÇÃO ARTÍSTICA NO ENSINO SUPERIOR: ESCRITA DIALÓGICA EM DEVIR
}

\section{NARRATIVES OF RESEARCH AND TRAINING IN ARTISTIC EDUCATION IN HIGHER EDUCATION: THE DIALOGICAL WRITING YET TO COME}

\author{
DOI: $\underline{\text { http://dx.doi.org/10.5965/1984317816012020008 }}$ \\ Ana Paula Caetano \\ UIDEF, Instituto de Educação, Universidade de Lisboa, Portugal \\ apcaetano@ie.ulisboa.pt \\ Ana Luísa Paz \\ UIDEF, Instituto de Educação, Universidade de Lisboa, Portugal \\ apaz@campus.ul.pt \\ Ana Rocha \\ Instituto de Educação, Universidade de Lisboa, Portugal \\ CIEBA, Faculdade de Belas Artes, Universidade de Lisboa, Portugal \\ rocha.ana@campus.ul.pt \\ Clara Marques \\ Instituto de Educação, Universidade de Lisboa, Portugal \\ claram@campus.ul.pt
}

\begin{abstract}
RESUMO
Neste artigo propomos produzir e analisar narrativas sobre experiências de escrita no ensino superior universitário, explorando e ampliando práticas de escrita narrativa dialógica. Realizada a oito mãos, a narrativa que se constrói e, subsequentemente, se procura analisar é submetida a uma reflexão contínua, polivalente, que exprime uma procura metodológica de exploração e ampliação das possibilidades da escrita formativa em educação artística. Por escrita dialógica, pretende-se frisar as potencialidades da construção de um texto que seja poliédrica, não hierarquizada, mas suficientemente fragmentada e entrecruzada para poder ser o reflexo de cada uma das autoras. Assume-se a narrativa como forma de pesquisa enquanto se escreve, uma escrita em devir e em diálogo pela qual se vai transformando a compreensão dos processos em análise e recriando os próprios processos de análise. Para além de uma reflexão teórica sobre a escrita e sobre as narrativas como processos de formação e investigação e de uma breve contextualização e apresentação metodológica, o artigo organiza as narrativas por temas, numa sucessão dialógica de textos de autoria individual, onde se mesclam discursos em prosa e poesia, comentados dialeticamente em textos conjuntos e posteriormente interpretadas do ponto de vista da formação e da investigação.
\end{abstract}

Palavras-chave: Narrativas de formação. Educação Artística. Ensino Superior. Escrita Dialógica.

\section{ABSTRACT}

In this article we propose to produce and analyze narratives about writing experiences in Higher Education, exploring and expanding dialogic narrative writing practices. The eight hands narrative that is constructed and subsequently sought to analyze is submitted to a continuous, multipurpose reflection that expresses a methodological search for an exploration and expansion of the possibilities of formative writing in artistic education. By 
dialogical writing, it is intended to emphasize the potentialities of the construction of a text that is polyhedral, not hierarchical, but sufficiently fragmented and intertwined to be the reflection of each one of the authors. The narrative is assumed as a form of research while writing, a writing in becoming and in dialogue through which the understanding of processes under analysis is transformed and recreating the processes of analysis itself. In addition to a theoretical reflection on writing and narratives as processes of formation and investigation and a brief contextualization and methodological presentation, the article organizes the narratives by themes, in a dialogical sequence of texts of individual authorship, with poetry and prose discourses, commented dialectically in joint texts and later interpreted from the perspective of training and research.

Keywords: Training narratives. Arts Education. Higher Education. Dialogic Writing.

desafiamo-nos a entrar com o outro em nós

e depois mais ainda quando outro a partir do ponto onde chegámos

nos incita

arquitetando pela escrita um diálogo que não sabemos onde leva

e se no centro desconhecido outro nos encontraremos sem respostas sós frente à vacuidade ou ao seu contrário

mas não antes da teia das palavras se tecer (Ana Viana / Ana Paula Caetano)

\section{INTRODUÇÃO}

Para a elaboração deste artigo, as quatro signatárias apresentam-se, primeiramente, na qualidade de envolvidas num Doutoramento em Educação Artística - duas enquanto docentes (APC - Ana Paula Caetano; ALP - Ana Luísa Paz) e duas como discentes (AR - Ana Rocha; CM - Clara Marques). Desde esta posição, propusemo-nos produzir e analisar narrativas sobre a escrita no ensino superior (nomeadamente escrita narrativa, mas não só). Temos como objetivo refletir sobre o papel da escrita na formação em educação artística e, em particular, explorar e ampliar práticas de escrita narrativa dialógica, que aqui são entendidas como processos investigativos colaborativos numa comunidade de aprendizagem onde se rompe com a tradicional hierarquização de poderes e saberes no ensino superior. Ensaiam-se formas de escrita diferenciadas da escrita científica mais comum, introduzindo uma linguagem poética e metafórica. 
Assumimos a narrativa como forma de pesquisa enquanto se escreve, uma escrita em devir e em diálogo pela qual vamos transformando a nossa compreensão dos processos em análise e recriando os próprios processos de análise. A narrativa como um espaço de criação com suas regras próprias, de temporalidade sequencial, num tempo mais ou menos dilatado, é complementada mas também confrontada pelo discurso sintético e atemporal da poesia e pelo discurso reflexivo e conceitual da meta-análise. A dialógica de textos que se justapõem é aprofundada por comentários que não a resolvem mas é também limitada por outros que procuram a dialética de sínteses, mesmo que provisórias. O individual e o coletivo lado-a-lado, sem se anularem, sem se dissolverem. Um movimento de insubordinação face ao estabelecido.

Nesse sentido, autores que normalmente não conversam entre si são aqui convocados para um diálogo connosco, a partir do que nos une a todos: a escrita ela-mesma.

O artigo apresenta dois pontos iniciais de reflexão teórica sobre escrita e as narrativas como processos de formação e investigação, depois dos quais se contextualiza a produção de narrativas e se apresentam as autoras. Seguem-se as narrativas, organizadas por temas e, em cada um deles, desenvolve-se uma sucessão dialógica de textos de autoria individual, alguns na forma poética, comentados dialeticamente em textos conjuntos. De seguida temos um interlúdio que reflete criticamente sobre o processo de escrita, com recurso a uma escrita metafórica. Posteriormente, as narrativas são interpretadas do ponto de vista da formação artística, em contexto do ensino superior. Por último, são apresentadas considerações finais sobre a própria construção do artigo como um processo formativo e investigativo.

\section{ESCRITAS EM DEVIR}

A escrita é matéria, pensamento e sentimento em ação feitos linguagem, em movimento, criando mundos novos que não existiam antes dela. Uma escrita em devir que nos faz devir com ela e que fica como uma criação, filho que segue o seu caminho próprio enquanto quem a criou segue um outro, muitos outros. E no devir 
da escrita inscreve-se a energia que nela se colocou, inquietação por vezes, divergência ou diversidade, de fragmentos que se combinam ou rasgam, deixando um rastro de caos e ordem à sua passagem. Nós, enquanto consciência, não nos queremos aprisionados nela, embora outras consciências - que nela se revêm ou revolvem - criem labirintos para nos prender a um tempo pretérito que já não é o nosso. Porque a escrita fica presente e nela uma presença se mantém e recombina com a presença de quem a revisita e ainda nela nos imagina.

Serve esta reflexão para dizer da violência e do prazer combinados, de nos sabermos pela escrita simultaneamente libertados daquilo que ao sair de nós nela se retém, embora nos bata, boomerang de volta a nós nos tempos mais inesperados. Violência também pelos limites, linearidade que desdobra o que é global e simultâneo, que desimplica e descompreende o que, num lampejo, sem ela se revela e se entende. Violência porque é regra, construção que nos formata, barreira que nos comprime, impedindo-nos de ver a plasticidade do que é além. Revelada pelas consequências naquele outro que a reflete dentro, e embora seja sua a escolha e a responsabilidade, e já não nossa - pois a nossa é só a da escrita; ficamos quase sempre indefesos perante o peso da culpa sobre nós lançada, por nos sabermos, lá no fundo, parte do processo dos que com ela se tocam ou sofrem. Violência ainda por a sabermos sempre aquém, um aquém nosso que fica registado e que às vezes ainda é, mesmo assim, além do que depois, nós, mais aquém, esquecidos do que antes já além conseguimos ir. Violência, pois, pela estranheza, mas também prazer de nos permitir transcender o que sem ela seríamos, à superfície.

Prazer-paixão, de agora mergulharmos com ela e desenovelarmos a nebulosa, que tantas vezes na pressa não nos damos o tempo para perceber e, muito menos, para compreender. Prazer e receio, pois sabemos que nos fará tropeçar, mais tarde ou mais cedo, melhor mais cedo que tarde, e que podemos lá ficar tempos infindos, caídos no nosso desacerto. Mais cedo ou mais tarde perdidos nalguma encruzilhada, na qual daremos voltas sobre voltas como numa rotunda, até decidirmos, incertos, mas necessariamente determinados a seguir por algum lado. $O$ inconcebível seria ficarmos parados. 
Uma aventura esta, a de partir com a escrita, feita da esperança nos encontros pelo caminho e do desconforto de sabermos que fora dela, nas margens e na floresta onde ela não entra, reside o que mais importa. Uma aventura esta, a de sabermos que muitas vezes a iremos largar e correr para longe dela, habitando os lugares dos quais the traremos imagens decepadas, memórias fragmentárias, impressões difusas. Iremos esforçar-nos por parecerem continuadas, harmónicas, coerentes. Será isso o que se espera de nós, mas se o fizermos sabemos que é um logro, uma mentira, e que seremos apanhados, num qualquer dia.

A única saída, a verdadeira, seria a do silêncio. Mas para esse não estamos preparados. Pois o pânico de não existirmos nele impede-nos de o aceitarmos. Será o terminus. Um dia inevitável. Mas não ainda. Para já, talvez, um silêncio intermitente. E um silêncio que se revolve dentro da própria escrita. Para que fique como uma saída, escape sempre para quando formos acusados de nos trairmos. Aí encontraremos o refúgio e a âncora onde nos afirmarmos fiéis a nós mesmos.

\section{ENQUADRAMENTO TEÓRICO - AS NARRATIVAS COMO PROCESSOS DE FORMAÇÃO E INVESTIGAÇÃO}

Pretende-se, neste artigo, desenvolver uma escrita dialógica e polifónica, como uma sucessão de textos de diferentes autorias, que têm simultaneamente uma dimensão narrativa e interpretativa, onde o encadeamento favorece uma triangulação reflexiva sobre os processos que vão sendo narrados, aprofundando e ampliando os sentidos construídos de compreensão das experiências conjuntamente vividas. Assumimos assim, que:

um enfoque narrativo dá prioridade a um eu dialógico, à sua natureza relacional e comunitária, pelo que a subjetividade é uma construção social, intersubjetivamente conformada pelo discurso comunicativo. $\mathrm{O}$ jogo de subjetividades, num processo dialéctico, converte-se num modo privilegiado de construir conhecimento (BOLÍVAR; DOMINGO, 2006, p. 23, parágrafo 100. Tradução nossa1).

\footnotetext{
1 Cf. O trecho original "un enfoque narrativo prioriza un yo dialógico, su naturaleza relacional y comunitaria, donde la subjetividad es una construcción social, intersubjetivamente conformada por el discurso comunicativo. El juego de subjetividades, en un proceso dialéctico, se convierte en un modo privilegiado de construir conocimiento."
} 
Trata-se de uma escrita onde a dimensão estética é valorada positivamente, para além da dimensão gnoseológica de construção de conhecimento, da dimensão metodológica de procura de novas formas de uso de narrativas na investigação, das dimensões ética e política de construção partilhada e participada de conhecimento.

Esta perspetiva política é assumida, ainda, pelo propósito de um trabalho conjunto entre docentes e discentes, em que todos tomam iniciativa sobre episódios a aprofundar e reconhecem o valor e poder do outro no decurso do texto.

Deste modo, a escrita narrativa faz emergir o seu potencial formativo, pois à medida que se avança dialogicamente no seu desenvolvimento vão-se construindo novos significados que à partida não se reconheciam, já que "a narrativa não apenas expressa importantes dimensões da experiência vivida, senão também, mais radicalmente, medeia a própria experiência e configura a construção social da realidade" (BOLÍVAR; DOMINGO, 2006, p. 98. Tradução nossa). Trata-se de um processo criativo, que mostra o processo enquanto acontece.

Tendo em conta o contexto em que esta experiência decorre, as narrativas e as vivências das autoras que aí estão associadas cruza-se assim com as propostas da Arts Based-Research (ABR), em concreto com algumas tentativas de remeter textualmente à metodologia mais específica da a/r/tografia (HERNÁNDEZ, 2008) para a sua (re)criação num formato de artigo. Arts Based-Research (ABR), ou Pesquisa Baseada em Arte (PBA) porque a investigação assume uma dimensão poética, dando ênfase, na escrita narrativa, à produção poética e metafórica enquanto linguagem autónoma de criação artística. A/r/tografia, mais especificamente, porque associamos num mesmo processo as dimensões da arte, da investigação e do ensino-formação (IRWIN, 2013). Desenvolvemos uma escrita da imagem imaginária e assumimos que a escrita coletiva entre professores e estudantes se constitui simultaneamente como um processo de formação e de investigação sobre a educação artística, onde arte e educação, investigação e formação se relacionam ora dialógica, ora dialeticamente, num movimento em que cada uma contém a outra sem se fundirem inteiramente e sem que nenhuma domine a outra (BALDACCHINO, 2015). 
Como bem revela a pesquisa realizada no âmbito do ensino superior, existe uma forte dimensão autobiográfica na formação dos saberes (ALMEIDA, 2012, p. 81), sendo a escrita - pode ser a de um diário -, sobretudo, a escrita colaborativa, reconhecida como um instrumento que envida a passagem de uma experiência pessoal para a sua transformação em conhecimento (ROLFE, 2009, p. 96).

Pretende-se, assim, uma escrita viva, que capte a sua vitalidade original, registada no momento em que emerge e se reescreve. Procura-se uma escrita vivificante, que "mergulha as coisas na vida do narrador para depois as ir buscar de novo" (BENJAMIN, 1992, p. 37) e que insemine com a sua força reflexiva um aprofundamento da experiência e do conhecimento. A sucessão de processos de escrita-leitura-(re)escrita provoca uma desfamiliarização, criando um dinamismo instável, pelo qual:

A configuração do texto em termos de estrutura iguala-se à refiguração pelo leitor em termos de experiência. Esta experiência viva consiste, por sua vez, numa verdadeira dialética, em virtude da negatividade que ela implica: des-pragmatização e desfamiliarização, inversão do dado na consciência imaginante, rotura de ilusão (RICOEUR, 1985, p. 309-310²).

Ao mesmo tempo, vai-se construindo uma memória coletiva, que nasce de memórias individuais em interação, conscientes nós de que são sempre reconstruções interpretativas eivadas do capital cultural de cada um e do conjunto formado por quem as produz. Versões parciais de verdades que se juntam, se confrontam e mesmo conflituam, para originar uma versão plural de um processo vivido em conjunto e para interrogar o próprio processo investigativo e formativo da escrita. Deste modo, em conjunto, integramos num mesmo trabalho a narrativa dialógica e poética, enquanto fenómeno que se investiga, como processo de investigação e também como modelo de formação reflexivo e criativo, visando e assumindo o saber como construção de linguagem, texto e comentário interpretativo que se desdobra sucessivamente:

\footnotetext{
2 Cf. O trecho original: "la configuration du texte en termes de structure s'égale à la refiguration par le lecteur en termes d'experience. Cette experience vive consiste à son tour en une véritable dialectique, en vertu de la negativité qu'elle implique: dépragmatisation et défamiliarisation, inversion du donné en conscience imaginante, rupture d'illusion."
} 
Saber consiste, pois, em referir a linguagem à linguagem. Em restituir a grande planície das palavras e das coisas. Em fazer falar tudo. Isto é, fazer nascer, por sobre a marca, o discurso ulterior do discurso. O que é próprio do saber não é nem ver nem demonstrar, mas interpretar (FOUCAULT, 1998, p. 50).

As palavras são usadas em duplo sentido: elas são o tempo presente - tão efémero - mas também se revelam na narrativa de arquivo, as narrativas que cada autora guardou consigo. Perante as escritas pretéritas não se deve ver uma verdade do texto. A aproximação ao momento da narrativa não lhe instila uma verdade necessária. Neste sentido, verdade e conhecimento nem sempre se encontram. É a vida da escrita que nos importa e onde ela nos pode levar. Importa assim, revelar que o nosso texto - como todos - transporta um sistema de regras. O qual permitirá a outros escrever textos análogos, pois ele mesmo incorpora e é, em última análise, uma metodologia (DERRIDA; WEBER, 1995 apud POPKEWITZ, 2019).

\section{METODOLOGIA - A ESCRITA CONJUNTA ENTRE PROFESSORES E ALUNOS DO DOUTORAMENTO EM EDUCAÇÃO ARTÍSTICA}

quando as palavras nos voltam como um boomerang e de repente as percebemos distantes fragmentadas começa a aventura rumo ao não-conhecido (Ana Viana / Ana Paula Caetano)

Narrativas, histórias vividas em conjunto, com sensibilidades distintas, com entendimentos diversos, com lugares comuns e incomuns na partilha e no diálogo que se vai operando pela sucessão de escritas a oito mãos, em devir.

Situamos as histórias numa história, a do Doutoramento em Educação Artística, iniciado no ano de 2016/17 na Universidade de Lisboa, um curso conjunto com a Universidade do Porto. Três anos letivos, três grupos de doutorandos, propostas curriculares similares, dinâmicas distintas e em devir, nunca se repetindo o que se repete por ser o processo decidido em conjunto e por serem os movimentos próprios. Propostas de escrita, a ampliarem-se a partir de um pequeno 
núcleo, onde a leitura e escrita de textos se entrelaçariam com experiências de educação artística, vividas pelos próprios ou observadas em terceiros. Os próprios são as docentes e discentes em três anos consecutivos. As autoras dos diversos textos são identificadas pelas suas iniciais: APC - Ana Paula Caetano; ALP - Ana Luísa Paz; AR - Ana Rocha; CM - Clara Marques.

Algumas narrativas foram escritas no decurso das Unidades Curriculares de Seminário I e de Metodologias e Práticas de Investigação II, do $1^{\circ}$ ano do Doutoramento em Educação Artística e remetem para as experiências aí vividas e para outras vividas em contextos educativos exteriores ao curso doutoral. Outras foram redigidas especificamente para este artigo e falam do processo da escrita na formação - uma escrita sobre a própria escrita. A escrita narrativa e poética surge como uma experiência artística de formação e investigação.

\section{APRESENTAÇÃO DE DADOS E REFLEXÕES: UM BAÚ DE HISTÓRIAS DE ONTEM, DE ANTES DE ONTEM E DE DEPOIS}

De seguida, neste ponto 5 , organizamos as narrativas em temas, sintetizados em títulos com um tom metafórico. Em cada tema começamos com um texto introdutório, onde se esboça o acontecimento em torno do qual, de seguida, se tecem, as diferentes narrativas individuais e os comentários coletivos.

O baú de dados analisados e discutidos em sala de aula remete, aqui, para a composição de textos onde as temáticas originais se subsumem ao corpo como tópica dominante. Fala-se, assim, de uma escrita que emana do corpo e da sua possível leitura, acerca do que faz o corpo, e ainda do advento de um novo corpo coletivo. O corpo da escrita torna-se, assim, um objeto de reflexão das experiências das autoras em múltiplas linguagens que são provenientes da escrita e se performatizam em dados contagiantes, que se interligam e se alastram através de um propósito de investigação. 


\subsection{A ESCRITA PARTILHADA SOBRE EXPERIÊNCIAS DE AULAS DINAMIZADAS PELOS DOUTORANDOS}

APC - Relembro a escrita a ganhar velocidade, com o peso da gravidade dos textos dos companheiros, professoras e colegas inspirados pelas práticas de aula dinamizadas por cada um, contributos a serem integrados depois pelos próprios em textos que cresciam em tamanho e densidade. Uma ideia que foi ganhando contornos inesperados, sugerida a partir de uma primeira experiência, e que foi transferida para as restantes. Um ritmo avassalador e do qual fui perdendo o pé, por nem sempre conseguir acompanhar a intensidade com que todos iam participando. Um fluxo de escrita que contagiou outras escritas, conjuntas entre professores e estudantes para publicações futuras, individuais ou em pequenos grupos, com partilhas e comentários que se mantém ainda hoje.

\subsubsection{O CORPO IMPLICADO NA PERFORMATIVIDADE E REFLEXIVIDADE COLETIVA}

APC e ALP - Uma das primeiras apresentações de textos, orientada por uma das doutorandas, Joana Andrade, foi particularmente marcante. A proposta era realizar uma performance, com um grupo de quatro voluntários, tendo os restantes participantes ficado a observar o evento, para posteriormente se abrir uma reflexão conjunta. A performance desenrolou-se à volta de uma mesa previamente organizada com um conjunto de objetos (uma jarra, uma pedra, uma pequena rede). Em fundo, escutava-se uma música de Leonard Cohen. Pedia-se que, em silêncio, fizessem uma coreografia com as mãos sobre a mesa e com os objetos, sem os pousar e interagindo de maneira a que estes circulassem entre os quatro participantes.

AR - Primeira ideia: o mote impulsionador da experiência do corpo no texto "The Body", escolhido do International Handbook of Research in Arts Education, e apresentado na sessão 10, onde se propunha que "Nas artes, o corpo é e sempre foi - lugar e o espaço de pensamento, conhecimento, performance e aprendizagem" (POWELL, 2007, p. 1083. Tradução nossa). 
$\mathrm{Na}$ sala 20, o espaço estava montado de forma diferente do habitual. O equipamento preparado. No centro uma mesa retangular e quatro cadeiras e, mais afastadas ao seu redor, as restantes cadeiras. A aluna apresenta-se no espaço com o corpo firme e empoderado no momento presente. Convida os colegas e professores a participar. Aceito de imediato. Ao meu universo aquela mesa é redonda. Preparo-me. Deixo-me ficar de pé e vejo a cadeira vazia. Os restantes elementos sentam-se. Mulheres. Sento-me. Ainda tenho alguma resistência no real equilíbrio espacial entre a cadeira e a mesa. Posiciono-me. Re-posiciono-me. Estamos prontas. Centro-me e leio a mesa com as mãos na ponta dos dedos. Sinto a temperatura, a memória e a alteração da horizontalidade. Arrasto as mãos e deixome ficar naquele espaço de ar. Sem som. Quero ficar. Liberto-me. Sigo o desafio.

Palavras que se movimentam no discurso, sons que se exaltam pela abertura de um sentido. Elementos que nos atraem às memórias que ecoam na pele em vibração, através de uma imagem a preto e branco de uma paisagem rochosa estampada no texto inicial. Naquele espaço demarcado pela forma da mesa, fomenta-se o encontro a três mãos, que entram e saem do espaço ar, lêem-se e coabitam, através de uma leitura visual. Olhos nos olhos. Apreende-se o desafio. Conquista-se o território do momento. Os participantes seguem as orientações verbais da condutora da ação, onde o corpo é o mutante protagonista que estabelece a ligação entre o corpo físico, emocional e holístico na educação artística.

O corpo apodera-se de mim, avança para a mão, estende-se pelo universo fora. $\mathrm{E}$ ali, ao som da água que me entorna, eu nado num mergulho já existente, flagrante. Tónico. Deixo de ser eu, passo a ser o momento. O momento em mim. Alcanço a pedra colocada no topo de uma jarra/tubo de ensaio. Pego na pedra, seca e arenosa. E, encaixada na palma da mão, sugiro-a a outra mão que a acolhe e explora. Tenho na mesa uma narrativa de vidro, água, pedra e rede. A rede do fogo, o vidro soprado, a areia que tempera, a água que seduz. A melodia que aparece. Leonard Cohen ouve-se. Vejo-me então. Levanto-me. Sento-me onde estavam os outros participantes observadores. Inicia o meu corpo falante a se mover. Permaneço fria. Exausta. Fecham-se-me os olhos por dentro. Quero respirar. Estou em observação. Observo. Exige uma participação. Distancio-me em mim. Ouço as 
vozes da partilha distantes, resistentes, quentes. Não consigo falar. O lado direito do meu corpo mexe autonomamente. Liga-se onde já esteve. Sou vibração. Sou ar.

$\mathrm{CM}$ - Procuro o meu registo daquela apresentação e encontro numa página solta A Dança, de Matisse, acompanhada pelas palavras de Foucault:

Posso ir até o fim do mundo, posso esconder-me, de manhã, debaixo das cobertas, encolher o máximo possível, posso deixar-me queimar ao sol na praia, mas o corpo estará sempre onde eu estou. Ele está aqui, irreparavelmente, nunca em outro lugar. O Meu corpo é o contrário de uma utopia, é o que nunca está sob outro céu, é o lugar absoluto, o pequeno fragmento de espaço com o qual, em sentido restrito, eu me corporizo. (FOUCAULT, 2013, p.7)

Dessa Dessa memória tento recuperar fragmentos do todo vivido. Na viagem do tempo evoco o momento. Fecho os olhos, respiro profundamente e torno-o presente no corpo. O silêncio do grupo e as palavras-guia que rompem o espaço e nos direcionam para o centro. Depois, já sentada, toco na pedra em cima da mesa. É lisa e fria na ponta dos dedos e depois na palma da mão. Outros olhos e outras linhas. Animados, dançam os pequenos objetos a medo até o enfraquecimento da consciência permitir a alegria do desconhecido e ampliar aquela coreografia improvisada. Gotas de água a cair. Um avião passa. O meu corpo só a ser. À nossa volta um círculo de pessoas, um corpo maior a pulsar. A sala totalmente preenchida pelo que é vazio e inteiro em simultâneo. A matéria a ocupar todos os espaços visíveis e invisíveis e a criar território, tempo e lugares sempre novos, ou talvez não.

Volto ao meu corpo.

Como naquele dia, sinto-me tudo.

APC - Intermitentemente o desdobramento. A consciência de um terceiro olhar criando movimento interno. A acontecer ao mesmo tempo. Todos lá, do lado de dentro. Todos lá, do lado de fora. Em planos sobrepostos. Todos no movimento das mãos. Todos no movimento do olhar. Todos no movimento da mente, que se pensa com as mãos e com o olhar. Ao mesmo tempo, mas não de igual modo. Nem sendo exatamente o mesmo momento aquele em que cada um se funde e desdobra. A história de cada um presente. O medo do outro presente. O prazer da expressão presente. A hesitação, a aproximação, o recuo, todos presentes. A expectativa, o 
espanto, a descoberta, presentes! A criação de algo que não havia antes, presentes. E depois, durante, antes, as ideias. Do que foi, do que é, do que poderia ter sido. Fragmentos de pensamento que retomamos, ligamos, aprofundamos. Continuando a descoberta, a criação, a conexão.

ALP - Em vez de recorrer à memória, percorro os arquivos e pondero sobre o facto de Joana Andrade, a doutoranda que dinamizou a performance, ter levado quase dois meses a compilar os comentários e a compor o seu próprio texto, profundamente afetado e entretecido com citações de grandes filósofos. Passaramse dois anos. Pergunto-me se ela ainda se recorda. Quanto a mim, o acontecimento veio depois. Ping ping ping, é cada vez mais cristalino o som da água a cair, estamos talvez numa gruta de cristais. O conhecimento pelo vivido faz-se presente e nenhuma das minhas interrogações toma corpo.

Talvez isso explique que nunca mais tenha entrado numa sala de aula sem o meu corpo. Posiciono-me, sei que sou eu mesma a pedra no charco que caminha e invade todo o espaço. Antes, apenas suspeitava da sua presença e não interrogava a sua placidez ou o acantonamento dos alunos por detrás de pesadas secretárias. Depois, o corpo pling aconteceu-me. Um dia estava em aula e o meu corpo estava lá. Pling. Nunca mais me abandonou.

Do baú dos pensamentos devidamente acautelados em word, recuperei o texto escrito no calor do momento. Perguntei mais do que respondi. ...Ploft Ploft Ping Resping, e eis o momento, de novo, eu à beira do lago da sabedoria a atirar mais uma pedrada no charco a perguntar o que pode um corpo? Foi essa pergunta que, no seu tempo Espinosa colocou e que Deleuze (1968) retomou, para que a pergunta ficasse suspensa entre nós, até hoje.

Corpos que se jogam, que se revelam, que se transformam. Ficarão presos na dança de encantamento do jogo?

\subsubsection{COMENTÁRIO - O CORPO DA ESCRITA}

Como tirar o corpo do que se é para o levar para o que se quer ser/saber - e antes mesmo de se saber já se sabe o que se quer saber? Terá já surgido esse tempo em que a vontade de saber toma conta do corpo? Como é que: 
...o evento se faz acontecer nas perguntas, na investigação, no texto?

...se põe o corpo dentro de um projeto, se realiza uma investigação (um processo, uma viagem) e isso resulta num texto (escrita, imagem, objeto...)?

.... corpo cria o texto?

..... texto diz o corpo? (Permitir-se-á que o texto fique aquém do corpo?)

... a tese não é só uma coreografia do já-dito, já-pensado, já-dançado?

Como de um encontro se passa ao outro encontro? Como é que se começa um diálogo inteligível com O Outro a partir do de dentro de si?

A intensidade da experiência do corpo implicado na relação vai criando um corpo coletivo que se desdobra em textos de fala e escrita que a refletem e dela se distanciam. A experiência da escrita amplia-se e intensifica a paixão de ser em relação. Mas desdobra-se a pontos de se ver de outra forma? Ou segue encantado consigo mesmo?

A tomada de consciência do corpo revela que ele serve de repositório e marcador de experiências e, em última instância, é nele que reside o conhecimento: nas células, fibras, nanomoléculas. Não dominamos inteiramente o processo, mas sabemos cada vez melhor onde o fazer despontar.

Não dominamos, aliás, nenhuma das partes do processo: há um arquivo físico e sensorial que se implanta, depois de uma escrita que já se escreveu a si mesma, tomando balanço a partir de si. Usamos uma linguagem que nos precede por completo, há séculos, e que se renova a cada palavra. É ela mesma um corpo denso. Por vezes, áspero e espinhoso. Outras vezes, macio, aveludado. Sempre misterioso. Há de ser por isso que se diz um mar de palavras, porque disto é feito o corpo da narrativa: ar, água, consciência de si.

\subsection{NOVAS ESCRITAS A PARTIR DA ESCRITA RETROSPETIVA DE EXPERIÊNCIAS EDUCATIVAS SIGNIFICATIVAS}

Talvez seja passageiro o desconforto da palavra ser e em nós o desacerto a descoberto espanto de não o vermos antes e a dor de não sabermos ainda como continuar

(Ana Viana / Ana Paula Caetano) 


\subsubsection{NA INTRA-RELAÇÃO, A SURPRESA E O ESPANTO}

APC - APC - Relembro um outro momento, onde escrevemos, professoras e estudantes, sobre processos de ensino aprendizagem significativos fora do contexto do Doutoramento. Partilhamos o que aprendemos nessa escrita, como estes textos se relacionavam com as leituras que decorriam e com os debates, os dilemas e as inquietações que nos suscitavam. Foi o ponto de partida para um aprofundamento noutras etapas, ligando com outras situações, com outras leituras, com os próprios projetos doutorais.

$\mathrm{CM}$ - Pegando em alguns textos escritos no primeiro ano do Doutoramento, centro-me no desconhecido, que me foi sempre tão familiar no trabalho profissional que desenvolvi, na intervenção com crianças com necessidades específicas. Estes, por natureza, e nem sempre por vocação, outsiders dos padrões convencionais tendencialmente normativos e as suas famílias (dizem alguns) vulneráveis, espelhos de estigmas endógenos e exógenos das sociedades onde se inserem, protagonistas constantes de impostas desobediências. Como poderíamos juntos, nessa altura, explorar novas estradas que nos levassem mais adiante?

Seguimos sem mapa, estabelecendo ligações de dentro para fora e de fora para dentro, dando voz às experiências, aos textos, silêncios e gestos que nos escolhem e se instalam organicamente em nós, fazendo dançar palavras, ideias, autores e conceitos, por vezes, num novelo só de pontas soltas, que tentamos ora em alegria ora em angústia desenredar, para the atribuir uma qualquer forma que nos possa aquecer e ainda que temporariamente, confortar as inquietações e para, logo de seguida, rasgar a peça porque já não nos serve para, enfim, voltarmos a tricotá-la neste processo (talvez) interminável.

Para aqueles de nós, comprometidos com uma educação democrática, colaborativa e com os argumentos em que a centralidade da produção artística e cultural na educação são também acerca de desconstruir para poder construir, importa aprender partilhadamente em contextos dentro dos quais diferentes tipos de relações humanas, baseados em diferentes formas de representação, são possíveis, nunca sendo garantidos. Sustem-se a possibilidade de que quem aprende (todos), 
possa recorrer também ao material simbólico das suas vidas diárias para recrear autorrepresentações sem necessariamente recircularem relações dominantes (GAZTAMBIDE-FERNÁNDEZ, 2013), numa arquitetura inesperada de retalhos sustentáveis habitados por narrativas-manta.

$$
\text { AR - Livro Dragão: a Voz das palavras - acção }
$$

$$
\begin{array}{r}
\text { O manuseio do objeto estabelece uma relação com as formas } \\
\text { das marcas deixadas na construção do livro. } \\
\text { As mãos participantes na decomposição das diferentes possibilidades do objeto } \\
\text { movimentam as transições entre os espaços, na procura de decisão da passagem } \\
\text { e a alteração da forma. } \\
\text { Em cada área criada, surge uma eventual narrativa que nos relaciona com a surpresa } \\
\text { da próxima viragem. } \\
\text { (livro de Ana Rocha) }
\end{array}
$$

O objeto livro é realizado como elemento de documentação da experiência vivida por um grupo de participantes na preparação de um workshop para o $3 .^{\circ}$ Seminário Diversidade, Educação e Cidadania (DEC3): Paisagens, Linguagens e Utopias na Cidade, realizado a 2 e 3 de junho de 2017 no Instituto de Educação da Universidade de Lisboa. Aqui o nosso grupo de doutoramento em educação artística (denominado O Buraco) apresentou um evento, e nele ficaram registadas palavras que ecoaram nas paredes e ressumem, projetadas no texto, no chão, nas mãos e pernas e braços dos que as pronunciam. Captadas no papel que delas fará memória, registo encontros com: partilha, cor, entre si e o outro, lambriónico. Registos documentais organizados num livro em forma de harmónio que se entremuta na horizontalidade ou na verticalidade de um infinito. O que ficará não importa. Mas o que foi, o que é no corpo e na consciência dentro da carne, dos ossos, do sangue é o que interessa. Esta impressão por debaixo da pele. Esta presença que nos envolve. Que nos faz sentir sermos mais. Sermos para além da pele. Sermos nos interstícios. Neste entre, sermos verdadeiramente.

No encadeamento de todos estes encontros/desencontros, existimos uns mais ausentes e outros mais presentes, numa dinâmica tangencial a um rizoma. Existimos para além de nós próprios neste evento, até porque o mote partiu ainda de quem, apesar de ausente, aqui pertence. Obrigada. 
APC - Última aula no seminário temático do Doutoramento em Formação de Professores: Diálogo em torno das questões éticas, partindo das interrogações, das reflexões, dos conceitos, das experiências dos alunos, em que tudo ia sendo desdobrado e articulado com diferentes referências teóricas, elas próprias, objetos de questionamento e desconstrução. Aprendemos uns com os outros. Que implicações para a educação artística? E que relação com as perspetivas do educador artístico Dennis Atkinson? Ser aqui e agora é ser na aventura de nos irmos construindo em intrarelação no todo de que fazemos parte. Somos no fluxo da relação, criamos o não conhecido e o não realizado. Na incerteza, no desequilíbrio, no repentino despertar reinventamo-nos, transgredimos as normas, transcendemos. Liberdade como valor supremo, em responsabilidades. Mas precisamos continuar a desconstruir nossos discursos e crenças. Também liberdade!

\subsubsection{COMENTÁRIO - HIPERTEXTO, UMA REDE DE ESCRITA VIVA}

Aprender paulatinamente o hipertexto, diálogo interpretativo que convoca os autores com os quais se vão criando laços e que se vão integrando na 'família' daqueles que nos suportam e desafiam. Uma família à qual a escrita dá corpo. Um corpo omnívoro que nos parece multiforme, mas que pode ser informe, a carecer de ser progressivamente esculpido, depurado e sintetizado. Um corpo à procura de si, que umas vezes se alinha, outras vezes se desconcerta. Por vezes, o hipertexto subsume-se à vontade de um só e todas as palavras se conjugam como se tivessem tido trazidas ao mundo para dizer, uma vez mais, ainda que com variações, o que já antes se pensava. Outras vezes, o hipertexto e suas infinitas combinatórias pegam na mão do autor, dos leitores, e levam-nos pelo universo, até ao nunca antes pensado. Outras vezes, como aconteceu agora mesmo, saem do texto em que escrevem, e provocam a escrita noutros espaços, tempos e imaginários. Descobrese sem surpresa que o espírito da escrita é contagiante, e perpassa não de professores para alunos, mas num circuito aberto, difuso. Uma vez provocada, a escrita acontece em qualquer lugar. Por exemplo, enquanto este texto era escrito, também as docentes, afetadas por esta experiência, provocaram e contagiaram a escrita noutros lugares. Hipertexto, então, também como uma rede de escrita viva. 


\subsection{A ESCRITA DE UM CAPÍTULO DE LIVRO COM 12 AUTORES}

APC - Relembro ainda a escrita coletiva para um capítulo de um livro. Tudo começou quando uma de nós foi convidada para participar da escrita de um livro sobre diversidade no ensino superior, coincidindo com o final do $2^{\circ}$ semestre do primeiro ano do Doutoramento. Em diversas aulas, os estudantes tinham introduzido práticas artísticas para partilharem suas leituras e reflexões, e com base nessa experiência decorria a preparação de um workshop sobre esses processos pedagógicos para um evento científico a realizar (retirado para manter anonimato na revisão por pares). Assumimos fazer um capítulo a 24 mãos (12 autores) centrado nessas práticas de aula e nesse evento, bem como nos projetos de Doutoramento em elaboração e através dos quais será possível estudar outros contextos onde as artes e a educação se cruzam. Posteriormente, não tendo sido possível aos organizadores do livro avançar com a sua publicação, optou-se pela sua revisão e apresentação num livro sobre Diversidade e Pedagogia do Ensino Superior (CAETANO et al., 2018).

\subsubsection{CONSTRUINDO UMA COMUNIDADE DE INVESTIGAÇÃO}

ALP - Foram 12 cabeças a rolar de contentamento por um capítulo acima. Primeiro era o Verbo, ou melhor, a Ideia, descritos um e outro por tópicos. Depois, a poesia foi escrita num caderno de encargos - quem escreve o quê e quantos parágrafos tem para o fazer. Houve escrita, reescrita e as docentes tiveram a última palavra a escrever, fazendo do acúmulo de parágrafos um tapete de entrançados. A imagem surgiu oportunamente e as fotos que fomos fazendo, sem grande intenção, ao longo de aulas e eventos tornaram-se novas dimensões da escrita, que se queria mais e mais artística.

$\mathrm{CM}$ - O desenvolvimento das unidades curriculares durante o primeiro ano deste Doutoramento encorpa em si o paradoxal e telúrico sentido entre a fluidez e o lume das discussões (filosóficas, profanas, por vezes poéticas) que nos trazem para fora da caixa numa aventura pedagógica por descobrir, do início até aqui. 
Um movimento de confluência, atração, contração e posterior expansão, que desobedece à expectativa tradicional do que poderia estar estabelecido e impulsiona eventos transformadores no rumo do coletivo.

Durante o hiato de tempo em que nos juntamos, vive-se como que numa cápsula extraordinária onde o que é temporal acalma e apenas os corpos, a palavra e a escrita se intrarelacionam em direção ao desconhecido (ATKINSON, 2015) que nos vai despenteando, umas vezes retirando lascas para se tornar mais leve e outras acrescentando seiva que adensa trajetórias e religa fendas, numa construção constante dos momentos críticos que ali vão acontecendo.

O processo do grupo vai-se estabelecendo, consolidando, serpenteando novas formas de encontro, dentro e fora das aulas. Dessa necessidade de partilha permanente, de procura, questionamento e de conexão, são criadas redes de diálogo digitais, abertas para o parto da comunidade.

Numa aula, inspirada por um dos nossos professores, surge uma imagem, a metáfora que foi de imediato apropriada e denomina, na sua generalidade, o primeiro grupo do Doutoramento em Educação Artística: O Buraco - em mim, espaço interno, profundo, para onde emergimos com as palavras que nos movem e as perguntas que nos chamaram a este lugar. Acolhedor, húmido, silencioso e em simultâneo musical tempo onde permanecemos com os amigos, reais e literários, que nos acompanham e nos desafiam nesta caminhada rumo ao incerto, onde nos debatemos com a luz e as sombras que nos acercam neste processo de encanto e rotura que é a aprendizagem (ATKINSON, 2015). Remetendo também as palavras para os outros que as pronunciam, ou melhor, que as emitem, as secretam, seguindo fluxos que às vezes se misturam e às vezes se distinguem (DELEUZE, 2010).

Desta maré é também composta a nossa comunidade de investigação, este não-lugar que inventámos e que nos vai inventando. Experiências individuais a desaguar num coletivo vivo cheio de vontades ou simplesmente, o prazer da descoberta, num voo partilhado.

AR e APC - Tenho o coração a arder dentro da estrutura do meu corpo e um silêncio pesado que me ofusca o interior, deixando-me sem visão. Um corpo 
maleável dentro do corpo que se expande e preenche o interior moldando-se a uma superfície côncava. Dou-me conta que sou um polvo, octo-pus, e os meus tentáculos escrevem por mim que não sou eu, mas muitos.

\subsubsection{COMENTÁRIO - PODE UM TEXTO DIZER DE TODAS AS VOZES?}

Podemos dizer que esta primeira experiência de escrita coletiva não é exatamente replicada no presente artigo, onde experimentamos cruzar novas fronteiras. Depois desta criação de uma voz que decorre de 12 individualidades, até se juntar num imenso Buraco onde múltiplas vozes se desdobram em escritas, comunicações em eventos, workshops, diferenciando-se em combinatórias diversas de autores, pretendemos agora saltar para um degrau em que declinamos a oportunidade de criar uma voz homogénea; queremos, quando muito, aproveitar a polifonia. Pode um texto dizer de todas as vozes que o compõem, sem perder o seu sentido? Pode o texto conter a forma de múltiplas narrativas que se sobrepõem e se alimentam num autor?

\section{INTERLÚDIO - QUEM LIGOU A REBARBADORA? SILÊNCIO, POR FAVOR!}

Em cada texto a sua vontade, e nessa se aloja uma experiência única e vibrante da revelação do que se acultura e consegue transpor a cada texto que se constrói. O entre-texto e o texto não escrito representam também uma construção orgânica e modelar em devir, de modo indisciplinado. Cabe aqui pensar como usar estas experiências textuais a partir das arts based-research, dos self-studies e das linhas invisíveis de teorias críticas e pós-críticas que aqui se encontram latentes. Com esse escopo, o martelo intensifica a linha cortante da crítica. Ao leitor chegará uma peça apolínea, de onde limalhas e aparos da existência foram varridos. Ainda se sente o cheiro do pó remexido, causado pelo burburinho das suas mãos afadigadas, já saindo de cena num silêncio brusco, apenas entrecortado por risinhos cúmplices que se afastam. Quer isso dizer que o texto-já-pronto diz menos do que aquele que, durante tanto tempo, foi pensado e construído por diferentes mãos.

Escrita como formação é também um exercício de cuidar da forma, no seu sentido mais profundo: reescrever até caírem todas as possibilidades de haver uma 
voz única, um texto homogéneo, ao mesmo tempo que se censura o gesto de censurar a crítica. Escrever um texto implica conter a possibilidade de outros textos e, no seu devir mútuo, esses objetos nascentes se interferem e interrompem.

Quem ligou a rebarbadora?
Silêncio, por favor!

O que pode ser a escrita da crítica se ela se faz a quatro vozes, oito mãos e sabe-se lá quantas almas? Cada uma, artífice especialista do seu instrumento, vai esculpindo. Primeiro cada uma na sua banda, depois fazendo a ronda e, finalmente, já delapidado livremente o que quer que esteja "a mais". Observar a escultura dum texto é contemplar o grande mistério da natureza do conhecimento em educação artística: se não há uma forma definitiva, como saber que a peça, o texto, a imagem, está terminada? Essas tecedeiras sem molde que trabalham um rizoma não sabem, não podem saber. A escrita escreve-se, cravada na pele.

Há um grupo que se junta para escrever, conversar, sentir as unhas e o cabelo crescer, ouvir o tempo ser e deixar de ser, até que o impulso de recomeçar se impõe. Ouve-se martelar ao longe... Já sabemos então que outro texto estará na forja.

\section{A ESCRITA NA EDUCAÇÃO ARTÍSTICA, EM CONTEXTO DO ENSINO SUPERIOR}

Por forma a ampliar a interpretação, centrada nos sentidos presentes nas narrativas acerca dos processos de escrita na formação em educação artística, em contexto do Doutoramento, retomamos os temas que os títulos organizadores enunciam:

- A escrita partilhada de experiências de aulas dinamizadas pelos estudantes

- O corpo implicado na performatividade e reflexividade coletiva 
- A escrita retrospectiva de experiências educativas significativas, transmutada em hipertexto e em novas escritas

- Na intra-relação, a surpresa e o espanto

- A escrita de um capítulo de livro com 12 autores

- Construindo uma comunidade de investigação

Retomamos, ainda, as metáforas que semeiam as narrativas e os seus comentários e que nos abrem os sentidos deste processo formativo:

- A narrativa como descoberta do desconhecido, viagem, voz em ação, tecedura sem molde

- As escritas juntas num baú de memórias e de palavras em diálogo, para além de coreografia do já dito

- O processo de reescrita e interpretação como um tecer e esculpir de texto, no corpo, cravado na pele, usando depois a rebarbadora cortante da crítica e acrescentando a seiva que adensa trajetórias e religa fendas

- O linguagem como um corpo denso, mar de palavras, acúmulo e renovação, que por vezes também se dissolve no ar

- A memória no corpo, conhecimento incorporado, presentificado no agora

- O corpo como fragmento de espaço em movimento, repositório de conhecimento, implicado no mergulho da escrita e da relação

- A procura de uma, duas, quatro, muitas vozes a procurar-se a solo, uníssono e polifonia, que se reconheçam na e para a escrita

- A comunidade de investigação como corpo maior, cápsula onde o que é temporal se acalma, espaço profundo onde deuses se acercam, onde se criam redes de diálogo, numa polifonia onde não se perde o sentido das vozes.

Cruzam-se, ao ler estes dois eixos de análise - temáticos e metafóricos diversas tensões que importa explicitar - as tensões que emergem do processo formativo e da escrita na formação e as tensões do processo da escrita no próprio artigo. Tensões que mantivemos dialogicamente ou que, por vezes, integramos em 
processos dialéticos. Desde já, as tensões entre registos descritivos e poéticos, entre textos narrativos e interpretativos. Tensões que passamos a evocar na forma de perguntas:

- Há verdadeiramente conversação ou justaposição de vozes? Entre nós, entre nós e os autores que revisitamos? Ou apenas ( $n$ )os usamos instrumentalizadamente para legitimar o que pensamos e fazemos?

- Será que derrubamos as barreiras e os desequilíbrios de poder entre professores e alunos, entre as autoras do texto? Será que a escrita ajudou a derrubar fronteiras? Será que queremos? Será que podemos? Será que nos permitimos?

- A interpretação do texto não é ainda, verdadeiramente, a interpretação dos nossos próprios textos à luz do processo formativo, não é análise do nosso discurso - precisaremos de um distanciamento maior para um outro nível de análise?

- Este todo, que não é igual à soma de todas partes, como se implica numa escrita diferenciada e contínua? Será que apenas se encanta, como na infância, com o som da sua própria voz? Será implicada e consequente?

- Da escrita à ação, das escritas em redor à escrita da tese, serão estas escritas bloqueios para outras, ou abrem o desejo e a disciplina de continuar noutras escritas e mergulhar nas teses?

- Há alguma especificidade da arte/educação artística que imprime forma a este processo? Seremos nós diferentes aqui e em contextos de formação de outras áreas? Qual a consequência dessa potencial diferença? Seremos mais ousadas nas nossas escritas? Haverá uma abertura e confiança maior para assumir o processo do encontro, a ignorância do não-conhecido, o devir?

Invocamos a teorização de JOSSO (2007) sobre as identidades existenciais, dimensões articuladas ao sensível e que decorrem do seu trabalho com histórias de vida, todas elas presentes na tecedura deste texto e na história coletiva da qual as quatro autoras deste artigo fazem parte: as dimensões do ser sensível, o ser da ação corporal, o ser das emoções, o ser de carne, o ser de atenção consciente, o 
ser de imaginação, o ser de afetividade e o ser de cognição. Assim, a formação em contexto de educação artística foi vivida nesta conexão complexa e tensional de dimensões individuais, interpessoais, grupais.

\section{CONSIDERAÇÕES FINAIS - A NARRATIVA DIALÓGICA NA INVESTIGAÇÃO, ROMPENDO FRONTEIRAS}

Escritas durante a formação, remetendo para um tempo antes desta, para o próprio tempo desta, para o tempo depois desta. Escritas posteriores à formação, comentando o tempo desta, as histórias desta, a própria escrita.

Continuamos o nosso processo formativo enquanto escrevemos coletivamente este e outros artigos. A escrita narrativa, de textos poéticos e de comentários sucessivos reatualizam a experiência em novas experiências de escrita, aprofundando a reflexividade e as aprendizagens sobre o vivido. Cada texto é vivo no texto do outro, que a partir dele recria, depura, intensifica e expande.

O individual e o coletivo diferenciam-se e indiferenciam-se, no diálogo através do qual se produz uma escrita conjunta que pretende apreender não apenas o fragmentário de cada acontecimento vivido mas visa compreender como os contextos e dispositivos sociais enformam a experiência ao mesmo tempo que são desafiados pelo desejo de nos libertarmos dos seus constrangimentos, criando uma realidade própria.

Em coautoria visamos assumir a autoridade sobre a nossa vida comum, sem anularmos a pluralidade numa dialética redutora, mas enfrentando o risco do comentário conjunto. Faltará porventura um sentido crítico maior, que só o distanciamento do tempo e de outras narrativas e interpretações posteriores permitirá. O sentido crítico é imanente ao risco de uma escrita que nos conduz sem sabermos à partida como, que nos pode dispersar e fragmentar e que se constrói enquanto caminhamos, rompendo as fronteiras do conhecido. Faltará a densificação do diálogo, que os limites de espaço físico para a escrita e de tempos conjuntos constrangem o - sempre inacabado - processo, a impelir-nos o movimento de continuar. 
Os tempos do processo narrativo - lembrar, narrar e refletir sobre o vivido - e da sua análise - pré-análise, leitura temática e leitura interpretativa-compreensiva, indicados por SOUZA (2014) a propósito de pesquisas por si desenvolvidas, interpenetram-se na escrita deste nosso texto, por serem os seus autores os mesmos e por se pretender uma escrita viva. Buscamos entrar na opacidade dos motivos para além da razão, e tocar no sentido e na sua dimensão pulsional originária (RICOEUR, 2014). Também por isso a narrativa ganha por vezes contornos de uma escrita poética, metafórica, fragmentada, ampliando sentidos e mantendo-os em aberto.

descobrimos no caminho
pequenos centros
dos quais irradiam fios
numa teia
olhares múltiplos que as histórias arquitetam
que se cruza com outras
adensando-se em sentidos
entre todos inventados
(Ana Viana / Ana Paula Caetano)

\section{REFERÊNCIAS}

ALMEIDA, Marta Mateus de. Desenvolvimento profissional dos docentes do ensino superior. Orientadora: Ângela Rodrigues. 2012. 438 f. Tese (Doutoramento em Educação Formação de Professores) - Instituto de Educação da Universidade de Lisboa, Lisboa, Portugal, 2013.

ATKINSON, Dennis. The adventure of pedagogy, learning and the not-known. Subjectivity, v. 8, n. 1, p. 43- 56. 2015.

BALDACCHINO, John. Art \pm education: The paradox of the ventriloquist's soliloquy.

Sisyphus: Journal of education, Lisboa, v. 3, n. 1, p. 62-79. 2015.

BENJAMIN, Walter. Sobre a arte, técnica, linguagem e política. Lisboa: Relógio d'Água, 1992.

BOLÍVAR, Antonio; DOMINGO, Jesús. La investigación biográfica y narrativa en Iberoamérica: Campos de desarrollo y estado actual. Forum: Qualitative Social Research, v. 7, n. 4, art. 12, 2006. Disponível em: http://ibposgrado.org/icuali/ La\%20investigacion \%20 biografica \%20y\%20narrativa\%20en\%20iberoamerica\%20\%20\%20. pdf Acesso em: 5 dez. 2019.

CAETANO, Ana Paula.; PAZ, Ana Luísa.; NARDUELA, Absalão.; PARDAL, Adriana.; ROCHA, Ana.; RÉ; Sofia.; CORREIA, Cinayana.; MARQUES, Clara; SILVA, Helena.; ANDRADE, Joana.; CARVALHO, Manuela; MEIRELES, Teresa. As Artes no Ensino Superior - 'Pedagogias do evento' no Doutoramento em Educação Artística. In: GONÇALVES, 
Susana; COSTA, José Joaquim (Eds.), Diversidade no Ensino Superior. Coimbra: CINEPIPCe, 2019. p. 239-260.

DELEUZE, Gilles. Sobre o Teatro: Um manifesto de menos e o esgotado. Rio de Janeiro: Jorge Zahar, 2010.

DELEUZE, Gilles.Spinoza et le problème de l'expression. Paris: Minuit, 1968.

FOUCAULT, Michel. As palavras e as coisas. Lisboa: Edições 70, 1998.

FOUCAULT, Michel. O corpo utópico, as heterotopias. São Paulo: n1 Edições, 2013.

GAZTAMBIDE-FERNÁNDEZ, Ruben. Why the arts don't do anything: Toward a new vision for cultural production in education. Harvard Educational Review, v. 83, n. 1, p. 211-237. 2013.

HERNANDEZ, Fernando H. La investigación basada en las artes. Propuestas para repensar la investigación en Educación. Education Siglo XXI, n. 26, p. 85-118. 2008.

IRWIN, Rita L. Becoming A/r/tography. Studies in Art Education, v. 54, n. 3, p. 198-215. 2013.

JOSSO, Marie-Christine. A transformação de si a partir da narração de histórias de vida. Educação, Porto Alegre/RS, v. 63, n. 3, p. 413-438, set/dez. 2007.

POPKEWITZ, Thomas. Historicizing how theory acts as 'the retrieval' apparatus in methods. In: FITZGERALD, T. (Ed.), Handbook of Historical Studies in Education: Debates, Tensions and Directions (22 pp.). Singapura: Springer, 2020, no prelo.

POWELL, Kimberly. Prelude. Moving from still life: Emerging conceptions of the body in arts education. In: BRESLER, L. (Ed.). International Handbook of Research in Arts

Education. Dordrecht: Springer, 2007. p. 1083-1086.

RICOEUR, Paul. Temps et récit. 3. Le temp raconté. Paris: Éditions du Seuil, 1985.

RICOEUR, Paul. O discurso da ação. Lisboa: Edições 70, 2014.

ROLFE, Linda. Using learner journals in teacher education in the arts. In: BURNARD Pamela; HENESSY, Sara (Eds.), Reflective practices in Arts Education. Dordrecht: Springer, 2009. p. 95-106.

SOUZA, Elizeu Clementino. Diálogos cruzados sobre pesquisa (auto)biográfica: análise compreensiva-interpretativa e política de sentido. Educação, Santa Maria, v. 39, n. 11, p. 39-50. 2014.

Este trabalho é financiado por fundos nacionais através da FCT - Fundação para a Ciência e Tecnologia, IP., no âmbito da Unidade de Investigação e Desenvolvimento em Educação e Formação Instituto de Educação, Universidade de Lisboa - UID/CED/ 04107/2019. 